American Journal of Animal and Veterinary Sciences 4 (4): 101-107, 2009

ISSN 1557-4555

(C) 2009 Science Publications

\title{
Detection of Listeria monocytogenes in Ready-to-Eat Meat Products
}

\author{
Asma M.M.A. Abdelgadir, Kunwar K. Srivastava and P. Gopal Reddy \\ Department of Pathobiology, College of Veterinary Medicine, \\ Nursing and Allied Health, Tuskegee University, Tuskegee Institute, AL 36088
}

\begin{abstract}
Problem statement: The objective of this study was to develop a rapid and sensitive method for the detection of Listeria monocytogenes and to screen large number of ready-to-eat (RTE) meat samples. Approach: A total of 250 fresh RTE meat samples of different varieties (chicken, turkey, beef, pork and cold cuts) were purchased from local grocery stores. Results: From the 250 total samples, 50 samples were randomly selected and subjected to DNA extraction, and immunomagnetic Separation (IMS) followed by RT-PCR analysis using primers against L. monocytogenes specific gene (hlyA). Five RTE samples negative by culture and by RT-PCR were spiked with L. monocytogenes (ATCC-19111) and used as positive controls. While all positive samples were detected as positive, all 50 samples were negative with both methods i.e., IMS followed by hlyA gene-based RT-PCR assay and the standard culture methods. Following this, all the 250 samples were tested by standard culture method as well as the IMS+RT-PCR assay. Five samples $(2.0 \%)$ were presumptively diagnosed as positive for Listeria on Oxford agar. All the five confirmed to be positive for L. monocytogenes by IMS+RT-PCR assay. Conclusion/Recommendations: The IMS + RT-PCR procedure was considerably more rapid and required only $28 \mathrm{~h}$ compared to $96-120 \mathrm{~h}$ for the conventional culture method. This method would be useful as the criteria for addressing the costly meat recalls and reducing outbreaks.
\end{abstract}

Key words: Listeria monocytogenes detection, immunomagnetic separation, real-time PCR

\section{INTRODUCTION}

Incidence of food-borne illnesses in both industrialized as well as in non-industrialized countrie $^{[1-5,10,22]}$ is increasing. This is probably due to major changes in food production, preservation, storage and consumption as well as in globalization and liberation of food trade and importation of foods. At the present there is a need for continuous surveillance of read-to-eat (RTE) food products to ensure safety to consumers in the industrial countries ${ }^{[1]}$. In the United States, food-borne illness causes over 76 million cases per year including 325,000 hospitalizations and 5,000 deaths at a projected cost of $\$ 233$ million $^{[15]}$. The cost of food recalls was estimated at $\$ 15$ million between 1985 and $1987^{[18]}$. Between the years 1993-1998, approximately $71 \%$ of all food product recall cases that occurred in the United States were the result of bacterial contamination ${ }^{[25]}$. Because of the severity of the disease listeriosis, many food producing companies are required by the federal agencies to routinely monitor the presence of this pathogen carefully.
Listeria monocytogenes is a gram-positive bacillus, facultative intracellular food-borne pathogen, ubiquitous in nature that can readily contaminate ready to eat food products such as vegetables, sea foods, dairy products and meats during or after the processing steps ${ }^{[6]}$. Among the thirteen antigenic serotypes of L. monocytogenes that are known, serotypes $1 / 2 \mathrm{a}, 1 / 2 \mathrm{~b}$ and $4 \mathrm{~b}$ represent about $90 \%$ of the isolates. Most of the outbreaks have been attributed to serotype $4 \mathrm{~b}$; nevertheless, in surveys of foods or foodprocessing plants for $L$. monocytogenes, serotype $1 / 2$ a strain was found most often ${ }^{[13]}$. It is very difficult to eliminate L. monocytogenes from Ready-To-Eat (RTE) products due to the ability of this organism to survive under adverse conditions such as low temperature for long periods.

A conventional method for detection of L. monocytogenes in foods is by primary enrichment followed by biochemical identification tests. These tests are laborious and require several days to confirm the presence of this organism. Due to the limited shelf lives of some food products, an alternative rapid, sensitive, inexpensive detection method is required. This is an

Corresponding Author: Kunwar K. Srivastava, Department of Pathobiology, College of Veterinary Medicine,

Nursing and Allied Health, Tuskegee University, Tuskegee Institute, AL 36088, USA

Tel: 334-724-4106 Fax: 334-724-4110 
important requirement for the confirmation of this pathogen in raw materials, the processing environments and RTE foods before their release into markets for human consumption. The drawbacks of conventional culture method can be overcome by using real-time PCR in which the pathogen can be detected and quantified by using a DNA binding dye, such as SYBR Green 1 or fluorescent probes ${ }^{[11]}$. However, this method still depends on the use of enrichment media to grow to a detectable level of organisms and to eliminate the food components that may inhibit the RT-PCR. Immunomagnetic Separation (IMS) is a technique that is used to concentrate target microbial cells from biological samples. It has been effectively combined with several biological methods, such as real-time PCR.

The disease listeriosis is responsible for approximately $27.6 \%$ of food-related deaths in the United States each year ${ }^{[15]}$ and $71 \%$ of all recalls of food products as a result to bacterial contamination in the United States between 1993 and $1998^{[25]}$. This led to regular microbial monitoring of RTE foods in environment-related sources. Because the infective dose of L. monocytogenes is unknown and is wide spread pathogenic nature, US Food and Drug Administration and the USDA, Food Safety and Inspection Service ${ }^{[22]}$ have issued a "zero tolerance" policy for the presence of L. monocytogenes in RTE foods ${ }^{[20]}$. It is the third cause of meningitis after $E$. coli and Streptococcus agalactiae ${ }^{[19]}$. While the incidence of human listeriosis is low at 2-15 cases per million and mortality rate in the USA about $20 \%{ }^{[12]}$ and in people with suppressed immune system, mortality rate might reach up to $75 \% \%^{[17]}$. Besides the other routes of transmission, different varieties of RTE foods are the main vehicle of transmission and a primary source of infection. Thus there is a need for continuous surveillance to ensure safety ${ }^{[1]}$ of the ready-to-eat meat products. The main objectives of this research are: (A) to determine the prevalence of $L$. monocytogenes in RTE foods that are distributed and sold in Macon and
Lee Counties in the State of Alabama, USA and (B) to compare the IMS followed by RT-PCR assay with the standard culture method of the USDA for the detection of L. monocytogenes.

\section{MATERIALS AND METHODS}

Sample design: The samples used in this study were RTE meats that did not require any further cooking prior to consumption. The categories of RTE meats purchased were: chickens, turkeys, pork and beef (smoked meat, deli cut luncheon, bologna, cooked bacon, roasted salami, ham, pepperoni, smoked franks, sausages, hot dog and tuna salad). A total of 250 samples were collected from four different major supermarkets in Macon and Lee counties of Alabama. Different RTE meat samples were purchased depending on which brands were available at the time of purchase in each store. In order to maintain a data base of the isolates, each store (Table 1) and RTE sample purchased were assigned an identifying number.

Media and supplement: A modified University of Vermont media (UVM) was used as primary enrichment medium (Remel, Catalog \#455252, Lenexa, KS) and Fraser Broth (FB) was used as secondary enrichment (Remel, Catalog \#668952), with its supplement (Fraser selective supplement, Remel, catalog \#663156). A selective agar base was used as a plating medium (Oxford formulation Remel, catalog \#668562) with its supplement (Modified Listeria Selective Supplement, Oxford, Remel, catalog \#664206). Brain Heart Infusion Broth (BHI) was used for the identification and isolation of Listeria spp. (Becton Dickinson, Catalog \#299070,Sparks, MD), Columbia Agar Base was used as a base to prepare Horse Blood Overlay Agar for confirmation of $L$. monocytogenes (Remel, Catalog \#663312) and Lysine CAMP Factor Discs (Becton Dickinson, Catalog \#21210, Lenexa, KS) were also used for confirmation.

Table 1: 250 ready-to-eat meat samples collected from different super markets in Lee and Macon counties of Alabama, USA. Samples were prepared/tested by conventional method

\begin{tabular}{|c|c|c|c|c|c|c|c|}
\hline Processing & Chicken & Turkey & Pork & Beef & Tuna & Vegetable & Total \\
\hline Smoke & 5 & 9 & 9 & 7 & & & 30 \\
\hline Deli & 25 & 23 & 6 & 8 & & & 62 \\
\hline Luncheon & 12 & 9 & 3 & 8 & & & 32 \\
\hline Franks & 6 & 6 & 4 & 10 & & & 26 \\
\hline Sausage & & 1 & 5 & 6 & & & 12 \\
\hline Hotdog & 9 & 5 & 3 & & & & 17 \\
\hline Bologna & 6 & 1 & 2 & 6 & & & 15 \\
\hline Bacon & 1 & 3 & 1 & & & & 5 \\
\hline Roasted & 5 & 4 & & & & & 9 \\
\hline Salad & & & 3 & & 4 & 1 & 8 \\
\hline Salami & 5 & & 1 & 1 & & & 7 \\
\hline Ham & & & 15 & & & & 15 \\
\hline Pepperoni & & & 8 & & & & 8 \\
\hline Total & 74 & 61 & 64 & 46 & 4 & 1 & 250 \\
\hline
\end{tabular}


American J. Animal \& Vet. Sci., 4 (4): 101-107, 2009

Table 2: Oligonucleotides used in RT-PCR assay for L. monocytogenes and target gene sequencing

\begin{tabular}{llll}
\hline Target gene & Name & Type & Sequence \\
\hline hly & hlAF & Forward primer & 5_-CAT GGC ACC ACC AGC ATC T-3 \\
& hlyA R & Reverse primer & 5_-ATC CGC GTG TTT CTT TTC GA-3 \\
\hline
\end{tabular}

Culture technique: For quality control purposes known cultures of L. monocytogenes (ATCC-19111) and L. innocua (ATCC-33090) were used. Both cultures were maintained in BHI with $20 \%$ glycerol broth and stored at $-80^{\circ} \mathrm{C}$. They were used as positive and negative controls. The immunomagnetic beads coated with monoclonal antibody against Listeria spp. (DYNAL ASA, Oslo, Norway) were supplied in suspension of PBS, pH 7.4 with $0.1 \%$ bovine serum albumin (BSA) and $0.02 \%$ sodium azide.

Primers used: The oligonucleotides targeting the listeriolysin $\mathrm{O}$ gene (hlyA), GenBank accession N0. M24199 $9^{[16]}$ were used in the study. The forward and reverse primers (Table 2) were synthesized by Integrated DNA Technologies, Inc., Coralville.

General methods: A total 250 RTE meat samples were first subjected to culture by the USDA method for detection of L. monocytogenes. All positive samples were further confirmed by RT- PCR. A total of 50 other samples were then selected randomly from these 250 samples and were subjected to IMS followed by RTPCR for comparison between conventional and rapid methods for the detection of L. monocytogenes in RTE meats.

Bacterial detection by cultural methods: The protocol used for detection, isolation and confirmation were the same as described by $\operatorname{USDA}^{[20]}$ which is shown below.

Primary enrichment procedure: The bags containing RTE meats were disinfected at the incision site by swabbing with $70 \%$ ethanol, $25 \pm 1.0 \mathrm{gm}$ of the sample was placed in a sterile Stomacher ${ }^{\mathrm{TM}}$ filter bag (Fisher Scientific, Pittsburgh, PA). A $225 \pm 5 \mathrm{~mL}$ primary enrichment of UVM (University of Vermont, USA) broth was added to above sample and was mixed for 2 min in a blender (Seward Stomacher \#400 Blender). The blended homogenate was then incubated at $30^{\circ} \mathrm{C}$ for $22 \mathrm{~h}$.

Secondary enrichment and direct plating onto Modified Oxford (MOX) agar: Secondary enrichment in Frazer Broth (FB) and direct plating on UVM was done in two steps:
- About $0.1 \mathrm{~mL}$ of the UVM enrichment was transferred to $10 \pm 0.5 \mathrm{~mL}$ of $\mathrm{FB}$ after adding the appropriate supplement and then tubes were incubated at $35 \pm 2{ }^{\circ} \mathrm{C}$ for $26-48 \mathrm{~h}$. If the suspected Listeria is present at this stage, it was represented by the change of broth color into black due to esculin hydrolysis

- As $0.1 \mathrm{~mL}$ of UVM broth was streaked over the surface of MOX agar for isolation, the plate was then incubated at $35+2^{\circ} \mathrm{C}$ for $26 \mathrm{~h}$

Two steps plating of $26 \mathrm{~h} \mathrm{FB}$ and examination of UVM-streaked MOX agar plate:

- As $0.1 \mathrm{~mL}$ of the FB was dispensed onto a MOX agar plate. The culture was then incubated at $35 \pm 2^{\circ} \mathrm{C}$ for $24 \mathrm{~h}$. The MOX agar plate or FB tubes without any degree of darkening were reincubated for another $24 \pm 2 \mathrm{~h}$

- The UVM streaked MOX agar plates were examined for colonies typical of Listeria spp. After $24 \mathrm{~h}$ of incubation, suspected colonies were seen as tiny white-grey colonies that were surrounded by a zone of blackening due to esculin hydrolysis. These colonies were transferred to Horse Blood Overlay Agar (HBOA) and incubated at $35 \pm 2$ for $24 \mathrm{~h}$. If no growth was observed, plates were reincubated for another $24 \pm 2 \mathrm{~h}$

Examination of MOX agar plates and interpretation/plating of 48 h FB: The FB tube's culture were re-examined after $48 \mathrm{~h}$ of incubation. Suspected colonies from MOX agar plate were examined for the presence of Listeria spp. Those showing dark colonies were swabbed or streaked on MOX agar plate and incubated as described earlier. If no darkening of FB was evident and no colonies were present on MOX agar and/or (HBOA) plates, the samples were considered negative for Listeria spp.

Isolation and purification procedures: A minimum of 20 colonies from suspected MOX plate were streaked on HBOA agar plates and incubated at $35 \pm 2^{\circ} \mathrm{C}$ for $22 \mathrm{~h}$ and then examined under light for presence of translucent colonies surrounded by a small zone of $\beta$ hemolysis. Then $\beta$ hemolytic colonies were isolated for confirmation. 
Confirmatory tests used to identify genus Listeria: The following three tests were carried out before proceeding to the final biochemical tests:

- Inoculation on special media. The $\beta$-hemolytic colonies were inoculated on BHI broth media and incubated for $18 \mathrm{~h}$ at $25^{\circ} \mathrm{C}$, to confirm purity

- Tumbling motility test. After incubation a wet mount was prepared for microscopy. If the wet mount exhibited small rods with active end-overend tumbling/rotating movement, it was considered confirmatory for Listeria spp.

- Purity test. The colonies were examined for morphological characteristics and organisms were subjected to Gram stain, Catalase test and the traditional $\beta$ Lysin CAMP factor test. These tests were used to re-confirm the major characteristic of the suspected isolate. After the confirmatory tests indicated presence of Listeria spp., it was further tested and re-confirmed by biochemical tests using API strips

Final confirmation by biochemical test using API Kit: The API strips manufactured by the Bio-Mérieux (France) can identify Listeria spp. These strips work on the principle of how the suspected bacterial samples ferment different types of sugar and/or produce enzymatic reactions. Based on the change in color of the sugars, a code is formulated which identifies the specific species strips. Identification scheme of Listeria spp. on the API Listeria system was same as was suggested by the manufacturer.

Rapid methods: After the pre-enrichment step, fifty (every $5^{\text {th }}$ sample) from 250 samples, were chosen randomly and tested by IMS followed by RT- PCR.

Immunomagnetic separation: From the preenrichment samples, $1 \mathrm{~mL}$ was taken from the filtered section after homogenization and placed in $1.5 \mathrm{~mL}$ micro-centrifuge tube into the Dynal MPC-S. A $20 \mu \mathrm{L}$ of the Dynabeads anti-Listeria antibody were added into each micro-centrifuge tube. The Dynal MPC-S rack was inverted 5 times and incubated at room temperature for 10 min with gentle continuous agitation to prevent the beads from settling. The magnetic plates were inserted into the Dynal MPC-S and the rack was inverted several times in order to concentrate the beads into a pellet. After $3 \mathrm{~min}$, the tubes were opened and the supernatant was discarded. The magnetic plates were removed from the Dynal MPC-S, a $1 \mathrm{~mL}$ of wash buffer (PBS-Tween) was added, the tubes were then incubated at room temperature with gentle continuous agitation for another $10 \mathrm{~min}$, again the magnetic plate was inserted into the Dynal MPC-S, the rack was inverted several times and after 3 min the supernatant was discarded. The magnetic plate was removed and the Dynabeads-Listeria complex was re-suspended in $100 \mu \mathrm{L}$ of wash buffer (PBS-Tween) and vortexed vigorously, later a $50 \mu \mathrm{L}$ was transferred onto two MOX plates, incubated at $37^{\circ} \mathrm{C}$ for $24 \mathrm{~h}$ or maximum $48 \mathrm{~h}$.

DNA extraction procedure: Individual colonies were picked from MOX agar plates and were used to inoculate culture tubes containing $5 \mathrm{~mL}$ of BHI broth and incubated at $30^{\circ} \mathrm{C}$ for $18 \mathrm{~h}$ without shaking. Genomic DNA was extracted using a DNeasy tissue kit (Qiagen Inc., Valencia, CA) using the manufacturer's protocol for gram-positive bacteria modified by adding freshly prepared lysozyme $\left(20 \mathrm{mg} \mathrm{mL} \mathrm{m}^{-1}\right)$. The cells were harvested in a micro-centrifuge tube, after centrifugation for $10 \mathrm{~min}$ at $5000 \mathrm{X} \mathrm{g}(7500 \mathrm{rpm})$ the supernatant was discarded; the bacterial pellet was resuspended in $180 \mu \mathrm{L}$ enzymatic lysis buffer and incubated for $30 \mathrm{~min}$ at $37^{\circ} \mathrm{C}$. A $25 \mu \mathrm{L}$ proteinase $\mathrm{K}$ and $200 \mu \mathrm{L}$ buffer was added and mixed by vortexing, then incubated at $70^{\circ} \mathrm{C}$ for $30 \mathrm{~min}$. A $200 \mu \mathrm{L}$ ethanol (96-100\%) was added to the sample and mixed thoroughly by vortexing. The mixture was then pipetted into DNeasy Mini spin column placed in a $2 \mathrm{~mL}$ collection tube, after centrifugation at $6000 \mathrm{X} \mathrm{g}$ for 1 min., the flow-through and the collection tube were discarded. Again the DNeasy Mini spin column was placed in a new $2 \mathrm{~mL}$ collection tube, $500 \mu \mathrm{L}$ buffer AW1 was added. The flow-through and the collection tube were again discarded after the centrifugation at $6000 \mathrm{X} \mathrm{g}$ for $1 \mathrm{~min}$. The DNeasy Mini spin column was placed in a new $2 \mathrm{~mL}$ collection tube and $500 \mu \mathrm{L}$ buffer AW2 was added; again the flow through and the collection tube were discarded after centrifugation for $3 \mathrm{~min}$. at 20,000 X g to dry the DNeasy membrane. The DNeasy Mini spin column was placed in a new $1.5 \mathrm{~mL}$ micro centrifuge tube and $100 \mu \mathrm{L}$ buffer $\mathrm{AE}$ was pipetted directly onto the DNeasy membrane, after incubation at room temperature for $1 \mathrm{~min}$. The mixture was centrifuged for $1 \mathrm{~min}$. at $6000 \mathrm{X} \mathrm{g}$ for elution. Then the elution step was repeated. The templates were stored in $50 / 50 \mathrm{BHI} / \mathrm{glycerol}$ broth at $-80^{\circ} \mathrm{C}$ until used.

Amplification and optimization of the real-time PCR conditions: Regions suitable for the design of L. monocytogenes-specific PCR primers were identified by aligning all hlyA sequences deposited in public databases by using the CLUSTALW multiple- 
alignment tool (European Bioinformatics Institute, EMBL; www.ebi.ac.UK). The BLAST-N tool (National Center for Biotechnology Information; www.ncbi.nlm.nih.gov) was used to confirm that none of the selected oligonucleotides (Table 2) recognized any registered DNA sequence other than the target sequence.

The forward and reverse primers hlyA (Table 2) amplifies a 64-bp fragment from the hlyA gene (positions 113-177) to achieve specific detection of L. monocytogenes. Prior to using in detection of L. monocytogenes in meat samples, the specificity of the primers was evaluated by RT-PCR using DNA isolated from the pure positive control. Preliminary studies also confirmed that the primers did not amplify DNA from other meat contaminants, e.g., Pseudomonas spp., Escherichia coli and Yersinia spp.

The RT-PCR reaction mixture $(25 \mu \mathrm{L})$ contained $1 / 2 \mu \mathrm{L}$ DNA template, $0.5 \mu \mathrm{L}$ of each primer and 12.5 of QuantiTect SYBR Green PCR Master Mix (Qiagen, Courtaboeuf, France) and $11 \mu \mathrm{L}$ Nuclease free water. The reactions were run with the following programs: $2 \mathrm{~min}$ at $50^{\circ} \mathrm{C}, 10 \mathrm{~min}$ at $95^{\circ} \mathrm{C}$ and 50 cycles of $15 \mathrm{~s}$ at $95^{\circ} \mathrm{C}$ and $1 \mathrm{~min}$ at $60^{\circ} \mathrm{C}$. The amplification results were visualized and analyzed using the soft ware provided with the thermocycler (iCycler MyiQ realtime PCR detection system; Bio-Rad Laboratories, Hercules, CA).

\section{RESULTS}

The presence of L. monocytogenes in a set of 250 samples of RTE meats taken from different stores in Macon and Lee Counties, AL was investigated using microbiological culture by USDA technique and IMS+RT- PCR. By means of IMS+RT-PCR no $L$. monocytogenes were found in the fifty samples that were taken randomly from the 250 samples. The same result was obtained by the standard methods. Where as out of the total 250 samples checked first by microbiological methods, L. monocytogenes was found in 5 samples (2\%), two deli chickens and one turkey deli meat, one turkey sausage and one beef frankfurter. They were further confirmed by IMS+RT-PCR. The result from the two methods supported the fact that different categories of RTE meats may be contaminated by L. monocytogenes. The higher prevalence from the total number of samples in this study was found to be in deli meat $3 / 250(1.2 \%)$, where as sausages and frankfurters have the same prevalence each $1 / 250$ $(0.4 \%)$ and no L. monocytogenes was found in the rest of processed RTE foods. Although L. monocytogenes was not found in meats such as smoked, luncheon, hotdog, bologna, bacon, roast beef and salad, only four L. innocua were isolated in some samples by conventional method. However, these samples did not give positive results in the IMS+RT- PCR. This indicates the high specificity of the primer sets used. In our study, we observed total of three rough Listeria colonies however; no attempt was made to confirm them to the species level.

\section{DISCUSSION}

The current USDA standard requires a "Zero tolerance" for the presence of L. monocytogenes in RTE foods. Presence of $L$. monocytogenes in meat was detected by using the USDA' s culture method and by IMS+RT-PCR. The conventional USDA method ${ }^{[20]}$ detected the presence of $L$. monocytogenes in meat samples after at least $90-96 \mathrm{~h}$ of incubation at $35^{\circ} \mathrm{C}$, where as RT-PCR detected L. monocytogenes between 28-30 h. This finding suggests that the IMS+RT-PCR method is suitable for rapid detection of $L$. monocytogenes in RTE products. Real-time PCR method also can provide more information about strain identification; this information is of great value in epidemiological and outbreak investigations.. Of the 250 samples of RTE foods tested, five samples were presumptively positive for L. monocytogenes on Oxford agar. These samples were positive for $L$. monocytogenes by means of biochemical tests, by API strip tests and also by IMS+RT-PCR tests using hlyA gene.

Deli meats have been found to contain high prevalence of L. monocytogenes, our present study therefore agrees with the study made USDA, FSIS and $\mathrm{FDA}^{[21]}$. Of the twenty RTE food categories that were studied, deli meat was found to have a higher risk of causing the disease in human populations. Other foods implicated were fresh soft cheese, frankfurters, pasteurized milk and mold-ripened cheese ${ }^{[7]}$.

In another study of RTE meats since 1989 USDA, FSIS and $\mathrm{FDA}^{[21]}$ has conducted testing of the finished products for L. monocytogenes and it was reported that $5.7 \%$ of deli meats such as sliced ham, $4.4 \%$ of frankfurters, $3.4 \%$ of salads and spread and $3.1 \%$ of roast/corned/cooked beef tested positive for the presence of L. monocytogenes.

In our study, one sample of turkey frankfurter was positive for L. monocytogenes. This suggests that the turkey frankfurters may carry this organism, which did cause death in a cancer patient. L. monocytogenes was found in an opened package of frankfurters from the patient's refrigerator $^{[3]}$. 
The main disadvantage of the use of Oxford agar is that, it cannot differentiate between pathogenic and non-pathogenic Listeria spp. hence it is very difficult to select L. monocytogenes for confirmation, since both of these organisms possess same phenotype and can be found in food samples. The L. innocua was used as a biological indicator in assessing appropriate thermal processing condition for L. monocytogene ${ }^{[9]}$. This is due to the similarity between the two spp. In our study, four samples were found to contain L. innouca. Besides the presence of other Listeria species such as L. innocua on selective media, there were also present Listeria-like organisms and Staphylococcus aureus. These organisms had the typical appearance of Listeria on selective media, but were non-Listeria species, as confirmed by IMS+RT-PCR and API Listeria strip (Bio-Mérieux, Co., France). From the other 50 samples examined, the developed hlyA gene-based IMS+RTPCR assay demonstrated comparable specificity and sensitivity between the currently used standard culture methods, but IMS+RT-PCR was considered more rapid which required $28-30 \mathrm{~h}$ compared to $96-120 \mathrm{~h}$ for the other method.

Food samples may contain Listeria other than L. monocytogenes; nevertheless the presence of Listeria-like organisms is another problem. In our study, three samples each contained Staphylococcus aureus. These organisms had the same appearance of Listeria spp. on Oxford agar, but they were not Listeria spp. when confirmed by API Listeria strip and IMS+RT-PCR. The RT-PCR is found to be more reliable than conventional method for identification of Listeria spp. because it is based on genetic characteristics, while the conventional method depends upon biochemical appearance ${ }^{[14]}$.

The RTE meats may contain food component that may serve as inhibitors for PCR amplifications and can lower its detection capacity. Therefore, preenrichment on UVM medium is an important step to precede the $\mathrm{PCR}^{[23]}$. In 1992 another investigator ${ }^{[7]}$ stated that the selective media are sometimes inhibitory and fail to recover injured/stressed cells. In our study, the RT-PCR method using the hlyA primers was done after a pre-enrichment in UVM broth, despite these previous reports, our hlyA RT-PCR method detected L. monocytogenes and achieved the same results as was obtained by the standard culture method. It was observed that the elimination of a preenrichment step decreased the overall detection time. There is a great concern in the food industry regarding the consumption of ready to eat meats that may be contaminated by L. monocytogenes. This organism is known to survive and grow under many adverse conditions including high salt concentrations, low refrigeration temperatures and low $\mathrm{pH}^{[1]}$. There is a great need to develop method(s) that can detect and identify Listeria spp. in raw materials, processing environments and the production batches, before the products reaches to the consumers.

\section{CONCLUSION}

In conclusion, this study compared the IMS+RTPCR method for L. monocytogenes detection with that of USDA standard culture method. The IMS+RT-PCR method was more rapid and sensitive. This method is useful for the rapid detection of L. monocytogenes in a reasonable period of time which may avoid costly recalls. Further research is needed to fully validate the IMS+RT-PCR method of this study against the gold conventional culture methods for routine testing of food-borne pathogens. The only disadvantage with this method is that it detects even the dead bacteria whereas standard culture method detects only the live bacteria.

\section{ACKNOWLEDGEMENT}

This investigation was supported in part by the United States Department of Agriculture's Cooperative State Research and Extension Service Teaching Grant NO., 2004-38820 -15142.

\section{REFERENCE}

1. CDC, 1985. Epidemiologic notes and reports listeriosis outbreak associated with Mexican style cheese-California. Morb. Mortal. Wkly. Rep., 34: 357-359.

http://www.cdc.gov/mmwr/preview/mmwrhtml/00 000562.htm

2. PubMed.gov, 1989. Listeriosis associated with consumption of turkey franks. Morb. Mortal. Wkly. Rep., 38: 267-268. PMID: 2495427

3. CDC, 2000. Multistate outbreak of listeriosisUnited States. Morb. Mortal. Wkly. Rep., 49: 1129-1130.

http://www.cdc.gov/mmwr/preview/mmwrhtml/m m4950a1.htm

4. PubMed.gov, 2001. Outbreak of listeriosis associated with homemade Mexican-style cheeseNorth Carolina. Mortal. Wkl. Rep., 50: 560-562. http://www.ncbi.nlm.nih.gov/pubmed/11456331

5. CDC, 2002. Public health dispatch: Outbreak of listeriosis-Northeastern United States. Morb. Mortal. Wkly. Rep., 51: 950-951. http://www.cdc.gov/mmwr/preview/mmwrhtml/m m5142a3.htm 
6. Beresford, M.R., P.W. Andrew and G. Sharma, 2001. Listeria monocytogenes adheres to many materials found in food-processing environments. J. Applied Microbiol. 90: 1000-1005. http://www.ncbi.nlm.nih.gov/pubmed/11412331

7. Bush, S.V. and C.W. Donnelly, 1992. Development of a repair enrichment broth for the resuscitation of heat injured Listeria monocytogenes and Listeria innocua. Applied Environ. Microbiol. 58: 14-20.

http://www.ncbi.nlm.nih.gov/pmc/articles/PMC195 $165 /$

8. Center for Food Safety and Applied Nutrition (CFSAN), 2000. Listeria Risk Assessment. http://www.foodsafety.gov/dms/lmrisk1.html

9. Fairchild, T.M. and P.M. Foegeding, 1993. A proposed nonpathogenic biological indicator of thermal inactivation of Listeria monocytogenes. Applied Environ. Microbiol., 59: 1247-1250. http://www.ncbi.nlm.nih.gov/pmc/articles/PMC202 269/

10. Fleming, D.W., M.D. Cochi, K.L. MacDonald and J. Brondum et al., 1985. Pasteurized milk as a vehicle of infection in an outbreak of listeriosis. N. Eng. J. Med., 312: 404-407. http://www.ncbi.nlm.nih.gov/pubmed/3918263

11. Fortin, N.Y., A. Mulchandani and W. Chen, 2001. Use of real-time polymerase chain reaction and molecular beacons for the detection of Escherichia coli O157: H7. Anal. Biochem. 289: 281-288. http://www.ingentaconnect.com/content/ap/ab/200 1/00000289/00000002/art04935

12. Gellin, B.G., C.V. Broome, W.F. Bibb, R.E. Weaver, S. Garenta and L. Mascol, 1991. The epidemiology of listeriosis in the United States-1986. Am. J. Epidemiol., $\quad$ 133: 392-401. http://www.ncbi.nlm.nih.gov/pubmed/1899779

13. Kathariou, S., 2002. Listeria monocytogenes virulence and pathogenicity, a food safety perspective. J. Food Protect., 65: 1811-1829. http://www.ncbi.nlm.nih.gov/pubmed/12430709

14. Lawrence, A.G., 1994. Incidence of Listeria spp. and Listeria monocytogenes in a poultry processing plant environment and in poultry products and their rapid confirmation by the multiplex PCR. Applied Environ. Microbiol., 60: 4600-4604. http://www.ncbi.nlm.nih.gov/pmc/articles/PMC202 027/

15. Mead, P.S., L. Slutsker, V. Dietz, L.F. McCaig and J.S. Bresee et al., 1999. Food-related illness and death in the United States. Emerg. Infect. Dis., 5: 607-625. http://www.ncbi.nlm.nih.gov/pubmed/10511517
16. Mengaud, J., M.F. Vicente, J. Chenevert and J.M. Pereira et al., 1988. Expression in Escherichia coli and sequence analysis of the listeriolysin $\mathrm{O}$ determinant of Listeria monocytogenes. Infect. Immunol., $\quad$ 56: 766-772. http://iai.asm.org/cgi/content/abstract/56/4/766

17. Nørrung, B., J.K. Andersen and J. Schlundt, 1999. Incidence and control of Listeria monocytogenes in foods in Denmark. Int. J. Food Microbiol., 53: 195-203. http://www.ncbi.nlm.nih.gov/pubmed/10634710

18. Roberts, T. and R. Pinner, 1990. Economic Impact of Disease Caused by Listeria monocytogenes. In: Foodborne Listeriosis, Miller, A.J., J.L. Smith and G.A. Somkuti (Eds.). Elsevier Science Publishers, Amsterdam, pp: 137-149.

19. Schlech, W.F., P.M. Lavigne, R.A. Bortolussi and A.C. Allen et al., 1983. Epidemic listeriosis evidence for transmission by food. N. Eng. J. Med., 318: 203-206.

http://www.ncbi.nlm.nih.gov/pubmed/6401354

20. Swaminathan, B., 2001. Listeria monocytogenes. In: Food Microbiology, Doyle, M.P., L.R. Beuchat and R.T.J. Montville (Eds.). ASM Press, Washington D C., USA. pp: 383-410.

21. USDA-FSIS., 1999. FSIS Notice (Listeria Guidelines for Industry). http://www.fsis.usda.gov/OA/topics/Imguide.html

22. Varnam, A.H. and M.G. Evans, 1991. Foodborne Pathogens: Illustrated Text. 1st Edn., Mosby Elsevier Health Science, ISBN: 10: 0815189761, pp: 557.

23. Wang, H., J.M. Farber, N. Malik and G. Saunders, 1999. Improved PCR detection of Campylobacter jejuni from chicken rinses by a simple sample preparation procedure. Int. J. Food Microbiol., 1: 39-45. http://www.ncbi.nlm.nih.gov/pubmed/10573390

24. Wong, S., D. Street, S.I. Delgado and K.C. Klontz, 2000. Recalls of foods and cosmetics due to microbial contamination reported to the US. FDA J. Food Protect. 63: 1113-1116. http://cat.inist.fr/?aModele $=$ afficheN\&cpsidt $=1460$ 517 